\title{
Effects of Photoacid Generator Concentration and Post-Exposure Bake Temperature on Dissolution Behavior of ArF Excimer Laser Resists
}

\author{
Kenichi Kanzaki ${ }^{1}$, Takeshi Ohfuji ${ }^{2}$ and Seiichi Tagawa' \\ 'The Institute of Scientific and Industrial Research, Osaka University, 8-1 Mihogaoka, Ibaraki, \\ Osaka 567-0047, Japan \\ -Semiconductor Leading Edge Technologies, Inc. (Selete), 292 Yoshida-cho, Totsuka-ku, Yokohama, \\ Kanagawa 244-0817, Japan
}

Keywords: chemically amplified resist, AFM, resist surface, development, acid diffusion, ArF excimer laser

\section{Introduction}

Chemically amplified resists are known as highly sensitive resists utilizing acid catalyzed reactions and play a significant role in lithographic processes. The acid catalyzed reactions produce hydrophilic groups that would interact with developer. The alkaline developer penetrates into the resist, reacting with hydrophilic groups and removes the resist materials successively [1]. The surfaces of developed resists have ultra small uneven structures reflecting the removal of resist materials. The edge roughness in the delineated resist patterns will affect directly the device characteristics, especially the nanodevice characteristics. Hence, the elucidation of the resist development characteristics is important.

In our previous work $[2,3]$, we investigated the exposure dose dependence of the surface topographic images of novolakdiazonaphthoquinone resists and chemically amplified $\mathrm{KrF}$ excimer laser resists. We have directed attention to the distribution of hydrophilic sites that influence the difference in the surface topographic images between novolak-diazonaphthoquinone resists and chemically amplified $\mathrm{KrF}$ excimer laser resists [3]. The hydrophilic sites are produced by acid catalyzed deprotection reactions in the chemically amplified resists [4]. The distribution of the generated hydrophilic sites may be closely related to the acid diffusion in the resist matrix. The acid diffusion is fundamentally significant in the chemically amplified resist system. The characteristics such as diffusion length have been studied experimentally [5-8]. It has been reported that the diffusion length of the generated acid is affected by post-exposure bake (PEB) conditions $[7,8]$. It is important to investigate the relation between the distribution of the hydrophilic sites and the dissolution behavior for better understanding of the dissolution characteristics of the chemically amplified resists.

In this article, the dependence of the developed surface structures of chemically amplified ArF excimer laser resists on the resist sensitivity and the exposure dose has been studied by using atomic force microscopy (AFM). The resist sensitivity was changed by the photoacid generator (PAG) concentrations and the PEB temperatures.

\section{Experimental}

The positive-type ArF excimer laser resists used here were a methacrylic resin-based chemically amplified resist and a commercially available resist, ZAF-001 (Nippon Zeone Co.). ZAF-001 was spincoated on Si wafers and prebaked at $115^{\circ} \mathrm{C}$ for $60 \mathrm{~s}$. The exposures were performed with an ArF excimer laser (wavelength of $193 \mathrm{~nm}$ ) at various exposure doses. Following the exposure, PEB was performed at 100,115 , and $130^{\circ} \mathrm{C}$ for $60 \mathrm{~s}$, respectively, resulting in the resists with different sensitivity. The exposed resists were developed using a $2.38 \%$ tetramethylammoniumhydride (TMAH) solution. The methacrylic resin-based chemically amplified resist was used for investigation of the concentration effect of PAG. Prebake at $120^{\circ} \mathrm{C}$ for $60 \mathrm{~s}$ and PEB at $120^{\circ} \mathrm{C}$ for $60 \mathrm{~s}$ were performed for the resists

Received November 1, 1999

Accepted December 15, 1999 
containing $0.5,1.0$, and $2.0 \mathrm{wt} \%$ PAG, respectively. Those resists were exposed to ArF excimer laser at various exposure doses. The development condition using a $2.38 \% \mathrm{TMAH}$ solution was same for each resist.

The microscopic structures of the resist surfaces were observed with AFM (SII Co.). AFM measurements were performed in the dynamic force (cyclic contact) mode. A Si cantilever (SII Co.) with a vibration frequency of $136 \mathrm{kHz}$ and spring constant of $14 \mathrm{Nm}^{-1}$ was used. The remaining film thicknesses of the developed resists were measured with a Surfcoder SE-2300 (Kobayashi Lab. Ltd.) in a contact mode.

The diffusion range of acids was measured by preparing two-layered resist of ZAF-001 with and without PAG. The resist without PAG was spincoated onto a silicon wafer to a film thickness of 0.5 $\mu \mathrm{m}$. The resist was prebaked at $115^{\circ} \mathrm{C}$ for $60 \mathrm{~s}$ and dried overnight. Then, the resist with PAG was spincoated on top of the PAG-free layer to a film thickness of $0.6 \mu \mathrm{m}$ and baked again at $115^{\circ} \mathrm{C}$ for $60 \mathrm{~s}$. The photo-generated acids diffuse from the PAGcontaining top layer into the PAG-free bottom layer, decomposing the inhibitor by acid catalytic thermal reaction, making the lower layer soluble to the developer. The interface may be not so sharp. However, the top layer was spin-coated on the bottom layer satisfactorily and the surface roughness of the two-layered resist was smooth as well as a monolayer one.

\section{Results and Discussion}

Figure 1 shows the contrast curve for the methacrylic resin-based chemically amplified resists at various PAG concentrations. The sensitivities were different at three PAG concentrations: $0.5,1.0$, and $2.0 \mathrm{wt} \%$. Figure 2 shows typical AFM topographic images of the resists. Figures 2(a)-2(c), 2(d)-2(f), and 2(g)-2(i) show the developed surfaces of the resist containing $0.5,1.0$, and $2.0 \mathrm{wt} \%$ PAG, respectively. Figure 2(a) shows the developed surface at a lower exposure dose $\left(6.1 \mathrm{~mJ} / \mathrm{cm}^{2}\right)$. The fine dissolution of the resist materials begins to appear in the relatively smooth surface, whereas the film thickness does not reduce yet. Such a developed surface was similarly observed in higher PAG concentrations as shown in Figs. 2(d) and 2(g). Figure 2(b) shows the surface at the exposure dose near the beginning of film thickness reduction (6.7 $\mathrm{mJ} / \mathrm{cm}^{2}$ ). The resist materials begin to dissolve and the developed surface become rougher. Similar developed surfaces were observed in higher PAG concentrations as shown in Figs. 2(e) and 2(h). The resist thickness reduces with increasing doses and

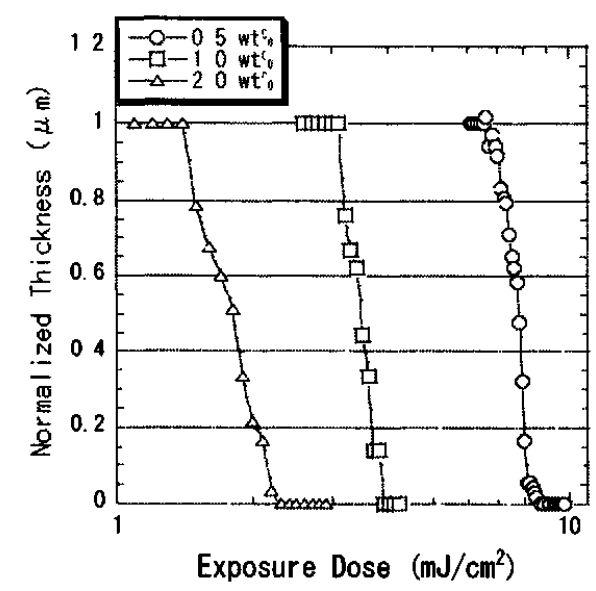

Fig. 1. Contrast curves for methacrylic resin-based chemically amplified resists at PAG concentrations: 0.5 , 1.0 , and $2.0 \mathrm{wt} \%$.
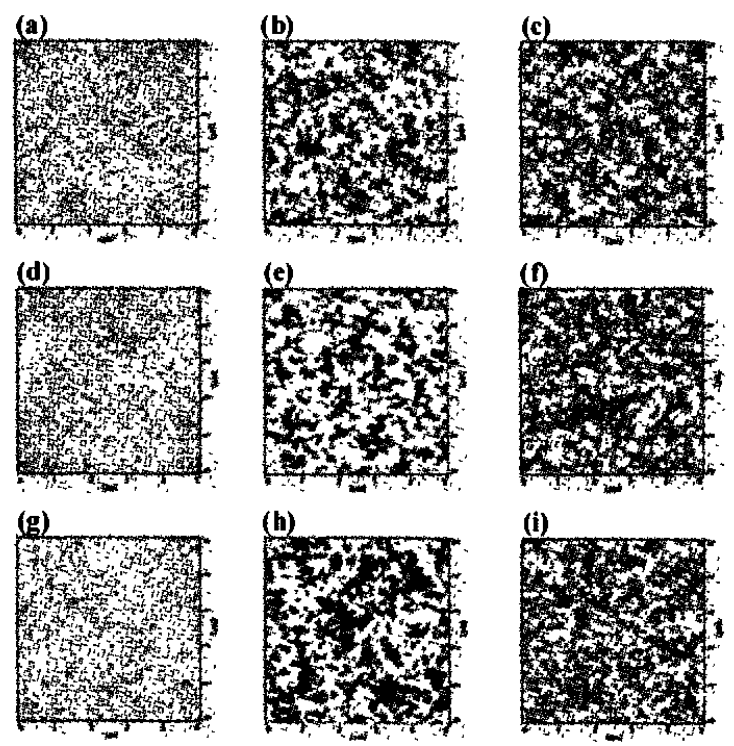

Fig. 2. Typical AFM topographic images $\left(5 \times 5 \mu \mathrm{m}^{2}\right)$ of developed methacrylic resin-based chemically amplified resists at PAG concentrations: (a) - (c) $0.5 \mathrm{wt} \%$, (d) - (f) $1.0 \mathrm{wt} \%$, and (g) - (i) $2.0 \mathrm{wt} \%$ and at exposure doses: (a) 6.1 , (b) 6.7 , (c) 7.5 , (d) 2.8, (e) 3.1 (f) 3.5 , (g) 1.3, (h) 1.4, and (i) $1.9 \mathrm{~mJ} / \mathrm{cm}^{2}$.

the developed surface after the reduction is shown in Fig. 2(c). The AFM topographic image of Fig. 2 (c) is in good agreement with the images of higher PAG concentrations shown in Figs. 2(f) and 2(i). Hence, the development procedure with increasing doses, Fig. 2(a)-2(c), 2(d)-2(f), and 2(g)-2(i), are considered to be the same. That is, the dependence of the resist dissolution behavior on the PAG concentration appeared very little in the AFM images. This result in Fig. 2 may be explained as follows. The acid is created by photo-induced reaction of PAG 
in the chemically amplified resist. The generated acids diffuse in the resist matrix and create hydrophilic (soluble in developer) sites by acid catalyzed decomposition reactions. The hydrophilic sites in the resist matrix reach a certain concentration, and then the resist materials begin to dissolve. The concentration to begin the dissolution may be constant in spite of the difference in the initial concentration of PAG. Hence, the AFM images of various PAG concentration does not appreciably vary.

The dependence of the PEB temperature on the resist development behavior was studied using a commercially available resist, ZAF-001. PEB temperature is closely related to the acid diffusion range $[7,8]$. Figure 3 shows the contrast curves for the resists at various PEB temperatures, 100, 115, and $130^{\circ} \mathrm{C}$, respectively. The sensitivities were different at three PEB temperatures. The typical AFM topographic images at those different sensitivity are shown in Fig.4. Figures 4(a)-(b), 4(c)(d), 4(e) correspond to PEB temperatures of 100, $115,130^{\circ} \mathrm{C}$, respectively. Figures $4(\mathrm{a}), 4(\mathrm{c})$, and $4(\mathrm{e})$ indicate the developed surfaces at lower exposure doses where the film thickness reduction dose not begin. The similarity is seen in those AFM images. That is, the small dissolved areas begin to appear in the relatively smooth surfaces. Figures 4 (b) and 4 (d) indicate the developed surfaces at exposure doses near the beginning of film thickness reduction. The AFM topographic image at $130^{\circ} \mathrm{C}$ was not observed, because the PEB at $130^{\circ} \mathrm{C}$ results in a high contrast and the resist materials dissolved completely in the narrow range from 0.6 to $0.7 \mathrm{~mJ} / \mathrm{cm}^{2}$. We compare the AFM images at the exposure dose near the film thickness reduction. Figs. 4(b) and 4(d) show the typical AFM topographic images at 100 and $115^{\circ} \mathrm{C}$. The observed AFM topographic images of these two conditions (PEB at 100 and $115^{\circ} \mathrm{C}$ ) usually indicated

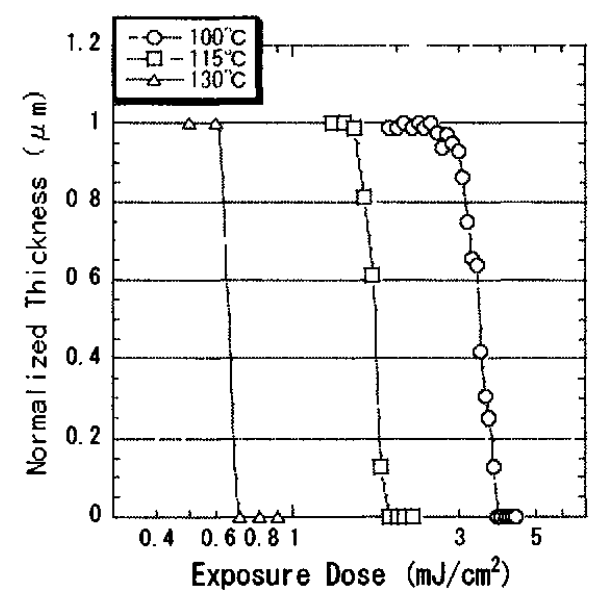

Fig. 3. Contrast curves for ZAF-001 at PEB temperatures: 100,115 , and $130^{\circ} \mathrm{C}$.
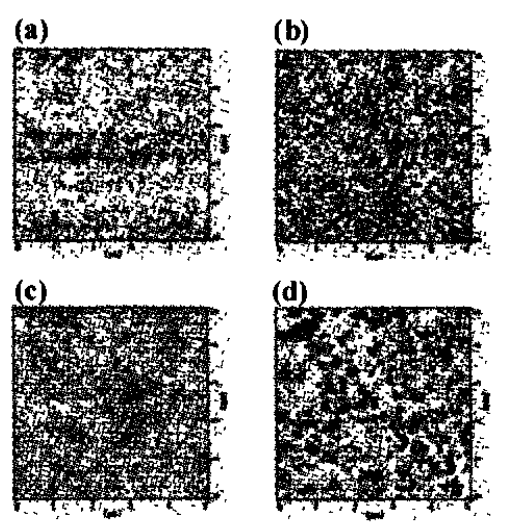

(e)

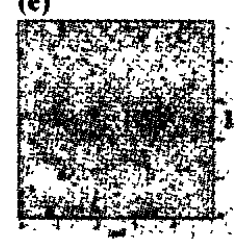

Fig. 4. Typical AFM topographic images $\left(5 \times 5 \mu \mathrm{m}^{2}\right)$ of developed ZAF-001 at PEB temperatures: (a) - (b) $100^{\circ} \mathrm{C}$ (c) - (d) $115^{\circ} \mathrm{C}$, and (e) $130^{\circ} \mathrm{C}$ and at exposure doses: (a) 2.3 , (b) 2.6 , (c) 1.4, (d) 1.5 , and (e) $0.6 \mathrm{~mJ} / \mathrm{cm}^{2}$.

the slight difference as shown in Figs. 4(b) and 4(d), though the difference was subtle. It is hard to decide the reason for this difference. The difference of PEB temperature, however, can be the main reason for the different dissolution behavior, because PEB temperature is the only difference in these sample preparations. Hence, this difference indicates that the acid diffusion range influenced the developed surface structures subtly. The effects of PEB temperature on the acid diffusion range were investigated. The relationship between the acid diffusion range and PEB temperature is shown in Fig. 5. The vertical axis indicates the thickness loss of the PAG-free bottom layer. The dissolved resist materials of the bottom layer were solubilized by the diffusion and the deprotection reactions of acids penetrated from the top layer. Hence, the thickness loss is correlated to the extent of the acid diffusion range. The relative difference of the lost thickness between 100 and $115^{\circ} \mathrm{C}$ is ca. $40 \mathrm{~nm}$ in experimental value. The difference in the diffusion range may be a factor that influences the resist dissolution behavior. The following explanation for the reason of the difference in the AFM topographic images may be proposed for instance. The distribution of the generated soluble groups in an acid diffusion area may not be appreciably homogeneous. The inhomogeneity may be enhanced under a certain condition such as high PEB temperature and low exposure dose. Whereas the increase in number of the hydrophilic sites by the extension of the diffusion 


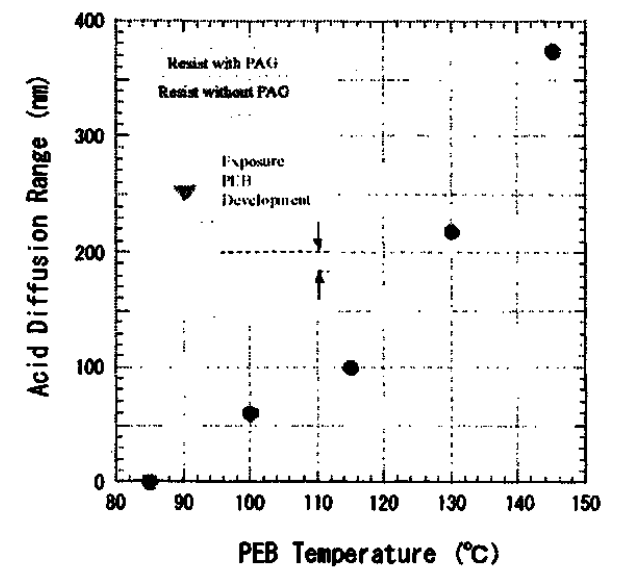

Fig. 5. PEB temperature dependence of diffusion range.

area would contribute to the promotion of the soluble link formation and the advancement of the sensitivity, the size and the distribution of the formed soluble links may vary widely with increasing diffusion range. The soluble link indicate the dissolution unit formed by connecting hydrophilic sites [2,9]. The variety of the size and the distribution of soluble links may be the reason for the difference in AFM topographic images of the resists.

\section{Conclusions}

In summary, we have studied dissolution behavior of chemically amplified ArF excimer laser resists by AFM measurement. The dependence of the surface structure of the developed resist on PAG concentration appeared very little in the AFM topographic images. However, the PEB temperature effect appeared to some extent in the AFM topographic images at the exposure dose near the beginning of film thickness reduction. This result suggests that the developed surface structures seem to be influenced by the acid diffusion range more than the initial PAG concentration. In addition, the dose dependence of the surface topographic images of the chemically amplified ArF excimer laser resists did not reveal such a drastic change that was previously observed in novolakdiazonaphthoquinone resist system.

\section{Acknowledgment}

The authors would like to express their gratitude to Mr. S. Seki at Osaka University for his cooperation in maintenance of AFM instruments, and to Mr. C. Y. Tseng and Mr. S. Tsuji at Osaka University for their assistance in exposure for the preparation of a two-layered resist sample.

\section{References}

1. J. P. Huang, T. K. Kwei and A. Reiser, Macromolecules 22 (1989) 4106.

2. K. Kanzaki, T. Ohfuji, M. Sasago and S. Tagawa, Jpn. J. Appl. Phys. 37 (1998) 6266.

3. K. Kanzaki, T. Ohfuji, M. Sasago and S. Tagawa, Jpn. J. Appl. Phys. 38 (1999) 2997.

4. H. Ito, C. G. Willson, Polym. Eng. Sci. 23 (1983) 1012.

5. L. Schlegel, T. Ueno, N. Hayashi, and T. Iwayanagi, J. Vac. Sci. Technol. B 9 (1991) 278.

6. D. MacKean, R. Allen, P. Kasai, U. Schaedeli and S. MacDonald, Proc. SPIE 1672 (1992) 94.

7. K. Asakawa, J. Photopolym. Sci. Technol. 6 (1993) 505

8. T. Itani, H. Yoshino, S. Hashimoto, M. Yamana, N. Samoto and K. Kasama, J. Vac. Sci. Technol. B 14 (1996) 4226.

9. K. Kamon, N. Nakazawa, A. Yamaguchi, N. Matsuzawa, T. Ohfuji, M. Sasago, K. Kanzaki, and S.Tagawa, Proc. SPIE 3333 (1998) 601. 